\title{
Clinical Outcomes of Physiologically-guided Revascularisation
}

\author{
Nasir Rahman, Ghufran Adnan, Awais Farhad, Jamshed Ali and Ihsan Ullah \\ Department of Medicine, The Aga Khan University Hospital, Karachi, Pakistan
}

\begin{abstract}
Objective: To assess the clinical outcomes of revascularisation based on fractional flow reserve (FFR) and/or instantaneous wave-free ratio (iFR).

Study Design: Descriptive study.

Place and Duration of Study: Department of Medicine, The Aga Khan University Hospital, Karachi from January 2012 to January 2020.

Methodology: A cohort of patients having moderate to severe coronary stenosis, undergoing coronary revascularisation based on invasive physiological assessment (FFR or iFR) were assessed. The participants were divided into the revascularisation-deferred group and the revascularization-performed group, based on the physiological results. Cox-proportional hazard model building was done, using a stepwise approach by assessing all plausible interactions and considering $p$-value $\leq 0.05$ as statistically significant.

Results: The frequency of major adverse cardiac event (MACE) and target vessel revascularisation was $8.4 \%$ and $3.2 \%$ in the revascularisation-performed group as compared to $6.4 \%$ and $3.2 \%$ in the revascularisation-deferred group. In adjusted models, no statistically significant difference was noted in MACE when comparing the revascularisation-performed group with a deferred group.

Conclusion: Revascularisation guided by invasive physiological assessment with FFR or iFR is clinically safe and led to better resource utilisation.
\end{abstract}

Key Words: Fractional flow reserve, Instantaneous wave-free ratio, Invasive physiological assessment, Low-middle income country.

How to cite this article: Rahman N, Adnan G, Farhad A, Ali J, Ullah I. Clinical Outcomes of Physiologically-guided Revascularisation. J Coll Physicians Surg Pak 2021; 31(11):1263-1267.

\section{INTRODUCTION}

Coronary artery disease (CAD) has emerged as the most common cause of death in low-middle income countries, including Pakistan. ${ }^{1,2}$ Coronary angiography has been the gold standard test to assess coronary stenosis; however, it explains the location and severity of stenosis only anatomically. ${ }^{3}$ There is also significant inter-observer and intra-observer variability in the reporting of stenoses. Recently introduced ancillary tests like fractional flow reserve (FFR) and instantaneous wave-free ratio (iFR) are significant tools for assessing the physiological significance of these stenosis. ${ }^{4,5}$ Physiological assessment of anatomically intermediate-to-severe stenosis, using iFR and FFR, has also been proven to reduce both the number of stents used and major adverse cardiac events. ${ }^{6-8}$

Correspondence to: Dr. Nasir Rahman, Department of Medicine, The Aga Khan University Hospital, Karachi, Pakistan

E-mail: nasir.rahman@aku.edu

Received: March 08, 2021; Revised: August 28, 2021;

Accepted: October 04, 2021

DOI: https://doi.org/10.29271/jcpsp.2021.11.1263
There is a higher prevalence of diabetes and multiple vessel coronary artery disease among the South-Asian population. ${ }^{9,10}$ Most of the studies on the use and outcomes of FFR/iFR have been conducted on the European/North American population. Consequently, there is a paucity of data on the utilisation and outcomes of FFR and iFR in the South-Asian population. ${ }^{11}$

\section{METHODOLOGY}

A longitudinal descriptive study was conducted from January 2012 to January 2020 in a cohort of patients with moderate to severe coronary stenosis at The Aga Khan University Hospital, Karachi. Patients in whom follow-up was not available and those who refused to undergo revascularisation after positive physiological assessment, were excluded. A final sample of 499 patientswasincludedinthestudy. Data wascollected retrospectively from the medical records of all the patients with intermediate-to-severe stenosis; and FFR or iFR was measured for the assessment of hemodynamic significance during the said period. Patients aged $>18$ years, presenting with moderate-to-severe stenosis on visual estimation of the coronary angiogram and a non-culprit vessel in patients presenting with the acute coronary syndrome were included. For patients with an FFR value of $>0.80$ and iFR value of $>0.89$, revascularisation was 
deferred, while it was performed where the values of FFR and $\mathrm{iFR}$ were $\leq 0.80$ and $\leq 0.89$, respectively. In case of dissociation in the FFR and iFR values, revascularisation was decided based upon the FFR cutoff.

Demographics and clinical characteristics of patients were assessed including comorbidities, medication history, previous history of $\mathrm{MI}, \mathrm{PCl}, \mathrm{CABG}$, atrial fibrillation, and stroke. The authors further noted the target artery along with mean FFR and mean iFR. The total numbers of FFR and IFR were recorded throughout the study period. Post-FFR procedures were documented. Information on the outcome was also collected for any event that occurred after the procedure as a major adverse cardiac event (MACE), including cardiac death, non-fatal myocardial infarction, and target vessel revascularisation. For this purpose, cardiac death was defined as any death in which a cardiac cause could not be excluded. Non-fatal myocardial infarction was defined according to the fourth universal definition of MI. Target vessel revascularisation (TVR) was defined as $\mathrm{PCl}$ or application of bypass grafts for restenosis of the previously-done FFR vessel. The study was commenced after approval was obtained from the Ethical Review Committee of the Hospital.

For the calculation of FFR/iFR, the Verrata plus coronary pressure guidewire (Philips Volcano, USA) 0.014 inch was inserted into the target artery. To achieve hyperemia during FFR measurement, continuous intravenous adenosine $140 / \mathrm{mcg} / \mathrm{Kg} / \mathrm{minute}$ was administered through a large bore cannula for 3-4 minutes. iFR was calculated using an automatic algorithm in the Philips volcano console. The follow-up data of all the patients were collected from clinic visits or telephonic interviews. The next of kin were interviewed in the case of patients who died. The clinical outcomes were compared with a median follow-up of 29 months.

Data was analysed using STATA software (version 14.2; StataCorp, College Station, TX). For descriptive analysis, mean and standard deviation were calculated for quantitative variables, while proportions were computed for qualitative variables. For quantitative variables, an independent t-test was used to compute the difference between the two groups after assessing normality. For inferential analysis, the groups of patients were compared for all their characteristics using the Pearson Chi-test and Fisher's Exact test (for qualitative variables). Cox proportional hazard model building was done using a stepwise approach, by assessing all the plausible interactions and considering a p-value $<0.05$ as statistically significant. In multivariable analysis with Cox proportional hazard regression, diabetes endured in the parsimonious model. In the patient-level analyses, MACE, target vessel revascularisation, non-fatal MI, and cardiovasculardeath were analysed with the association of negative and positive iFR, adjusted for other variables. Kaplan-Meier curves of MACE, target vessel revascularisation, non-fatal MI and cardiovascular death with negative and positive FFR or iFR were compared with the log-rank test.

\section{RESULTS}

The mean age was $62.8 \pm 10.80$, and $71.9 \%$ of the patients were males. Baseline characteristics of both the groups were similar, but for the prior history of revascularisations as, shown in Table I.

The utilisation of invasive physiological assessment was $<10 \%$. The most common indication for physiological assessment was non-culprit artery stenosis in acute coronary syndrome $(44.7 \%$, $n=223$ ). Twenty-two percent of the patients had moderate-to-severe LV dysfunction (ejection fraction $\leq 45$ ).

The coronary angiogram indicated multivessel disease in $70.1 \%(n=350)$ of the cases. The most assessed artery was LAD (61.3\%), followed by RCA (19\%, Table I). Of the patients with angiographically severe stenosis, and who would have undergone revascularisation, the procedure was deferred in $43 \%$ (Figure 1).

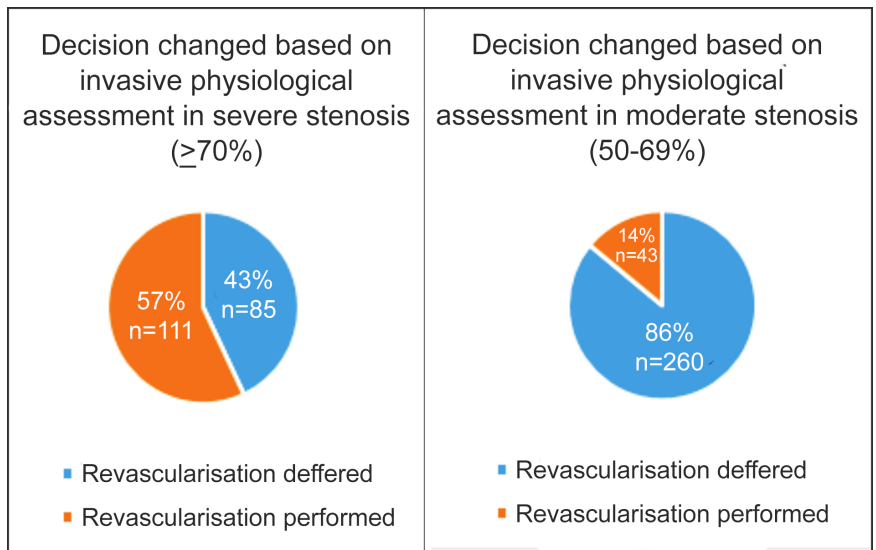

Figure 1: Change in decision based on invasive physiological assessment.

Among patients having angiographically moderate stenosis, thus not indicated for revascularisation, 14\% proceeded for revascularisation based on physiological severity (Figure 1). Revascularisation of the assessed artery was performed percutaneously in $85 \%$ and surgically in $15 \%$ of the FFR/iFR-positive group of patients. On multivariate regression analysis, diabetes ( $\mathrm{HR}=2.80,95 \%$ C.I: $1.32-5.94, \mathrm{p}=0.007)$ was an independent predictor ofadverse outcomes.

The Kaplan-Meir method did not indicate a statistically significant difference of MACE between the revascularisation-deferred group $(6.4 \% n=22)$ and revascularisation-performed group $(8.4 \% n=13)$, as shown in Figure 2. The Kaplan-Meier curves are shown for the comparison of MACE, target vessel revascularisation, non-fatal MI, and cardiovascular death (Figure2).

\section{DISCUSSION}

In this study, the decision of revascularisation was changed, based on physiological assessment in approximately a quarter of the cases.

In the present study, MACE rates were similar on event-free survival in both the revascularisation-performed and the revascularisation-deferred groups, as shown in Figure 1.

As proved in previous literature, the decision making regarding coronary intervention can be misguided by visual angiographic estimation of coronary lesions. ${ }^{3}$ 
Table I: Baseline and procedural characteristics of patients of study population.

\begin{tabular}{|c|c|c|c|c|}
\hline $\begin{array}{l}\text { Baseline } \\
\text { characteristics }\end{array}$ & $\begin{array}{l}\text { Total Cohort } \\
n=499\end{array}$ & $\begin{array}{l}\text { Revascularisation } \\
\text { deferred group } \\
n=345(69 \%)\end{array}$ & $\begin{array}{l}\text { Revascularisation } \\
\text { performed group } \\
n=154(31 \%)\end{array}$ & p-value \\
\hline Age ( \pm SD years) & $62.8 \pm 10.80$ & $62.6 \pm 11.05$ & $63.2 \pm 10.23$ & 0.589 \\
\hline Gender (male) & $359(71.9 \%)$ & $245(71 \%)$ & $114(74 \%)$ & 0.489 \\
\hline Diabetes & $251(50.3 \%)$ & $169(49 \%)$ & $82(53.2 \%)$ & 0.379 \\
\hline Dyslipidemia & $263(52.7 \%)$ & $185(53.6 \%)$ & $78(50.6 \%)$ & 0.539 \\
\hline Smoker & $86(17.2 \%)$ & $60(17.4 \%)$ & $26(16.9 \%)$ & 0.890 \\
\hline COPD & $27(5.4 \%)$ & $19(5.5 \%)$ & $8(5.2 \%)$ & 0.887 \\
\hline Prior CABG & $12(2.4 \%)$ & $12(3.5 \%)$ & 0 & 0.022 \\
\hline Prior Stroke & $18(3.6 \%)$ & $12(3.5 \%)$ & $6(3.9 \%)$ & 0.817 \\
\hline Prior $\mathrm{PCl}$ & $86(17.2 \%)$ & $67(19.4 \%)$ & $19(12.3 \%)$ & 0.053 \\
\hline History of atrial fibrillation & $14(2.8 \%)$ & $12(3.5 \%)$ & $2(1.3 \%)$ & 0.244 \\
\hline \multicolumn{5}{|c|}{ Indication for procedure } \\
\hline ACS & $223(44.7 \%)$ & $151(43.8 \%)$ & $72(46.8 \%)$ & 0.536 \\
\hline CCS I & $3(1 \%)$ & $3(1.5 \%)$ & 0 & $<0.001$ \\
\hline Aspirin & $492(98.6 \%)$ & $338(98 \%)$ & $154(100 \%)$ & 0.106 \\
\hline Clopidogrel & $375(75.2 \%)$ & $233(67.5 \%)$ & $142(92.2 \%)$ & $<0.001$ \\
\hline Statin & $494(99 \%)$ & $340(98.6 \%)$ & $154(100 \%)$ & 0.330 \\
\hline Beta blocker & $410(82.2 \%)$ & $273(79.1 \%)$ & $137(89 \%)$ & 0.008 \\
\hline Calcium channel blocker & 99(19.8\%) & $74(21.4 \%)$ & $25(16.2 \%)$ & 0.177 \\
\hline ACE inhibitors/ARBs & $200(40.1 \%)$ & $137(39.7 \%)$ & $63(40.9 \%)$ & 0.801 \\
\hline \multicolumn{5}{|l|}{ Ejection fraction } \\
\hline $\mathrm{EF}<30 \%$ & $47(9.4 \%)$ & $31(9 \%)$ & $16(10.4 \%)$ & \multirow{2}{*}{0.635} \\
\hline EF $30-45 \%$ & $63(12.6 \%)$ & $41(11.9 \%)$ & $22(14.3 \%)$ & \\
\hline \multicolumn{2}{|c|}{ Angiographic findings and revascularisation } & $\begin{array}{l}\text { Revascularisation } \\
\text { deferred group } \\
n=345(69 \%)\end{array}$ & $\begin{array}{l}\text { Revascularisation } \\
\text { performed group } \\
n=154(31 \%)\end{array}$ & p-value \\
\hline \multicolumn{5}{|c|}{ Disease severity on visual angiographic assessment } \\
\hline Moderate stenosis $(50-69$ & & $260(75.4 \%)$ & $43(27.9 \%)$ & $<0.001$ \\
\hline RPDA & & $2(0.6 \%)$ & 0 & $<0.001$ \\
\hline \multicolumn{5}{|l|}{ FFR/iFR value } \\
\hline Mean FFR & & $0.88 \pm .05$ & $0.75 \pm .04$ & $<0.001$ \\
\hline Mean iFR & & $0.94 \pm .03$ & $0.81 \pm .07$ & $<0.001$ \\
\hline \multicolumn{5}{|c|}{ Post physiological assessment intervention } \\
\hline \multicolumn{2}{|c|}{$\mathrm{PCl}$ only to FFR measured lesion } & 0 & $84(54.5 \%)$ & \multirow{4}{*}{$<0.001$} \\
\hline \multicolumn{2}{|c|}{$\mathrm{PCl}$ only to FFR non-measured lesion } & $161(46.7 \%)$ & 0 & \\
\hline \multicolumn{2}{|c|}{ CABG } & $4(1.2 \%)$ & $24(15.6 \%)$ & \\
\hline \multicolumn{2}{|c|}{$\mathrm{PCl}$ to both FFR measured and non-measured artery } & 0 & $46(29.9 \%)$ & \\
\hline
\end{tabular}

In this study, the change in the decision regarding revascularisation observed was $24.6 \%$, similar to that reported by Ripcord $(26 \%)$ and Famous NSTEMI (21\%). ${ }^{12,13}$ However, in other studies such as the Pressure-wire study (34\%) and POST-IT (45\%) study, the numbers are as high as $45 \% .{ }^{14,15}$ This emphasised that invasive physiological assessment can guide decision-making by crossing patients over to better suited therapeutic strategy.

The MACE rates in the three-year follow-up of FAME 2 trials were $10.1 \%$ in the $\mathrm{PCl}+\mathrm{MT}$ group (FFR positive + $\mathrm{PCl}$ group), similar to this study with MACE rate of $8.4 \% .{ }^{16}$ In the COFFRS study from India, the revascularisation group had MACE rate of $2.28 \%$ at 18 months follow-up. ${ }^{17}$ This difference in outcomes compared to COFFRS can be explained by the older age group (mean age 62.8 vs. 56.3 years), longer follow-up period (29 months vs. 18 months), and the relatively higher number of ACS patients (44.7\% vs. $14 \%$ ) in the present cohort. ${ }^{17}$

The physiological assessment-based treatment not only minimises the number of unnecessary interventions, but also leads to better allocation of limited resources in a low- to-middle-income country. This utilisation should be increased considering the pronounced economic and clinical benefits of using physiological assessment in decision-making. In the present data on multivariate analysis, the independent predictor of a MACE event was the presence of diabetes, consistent with the data from prior studies. ${ }^{18,19}$ 

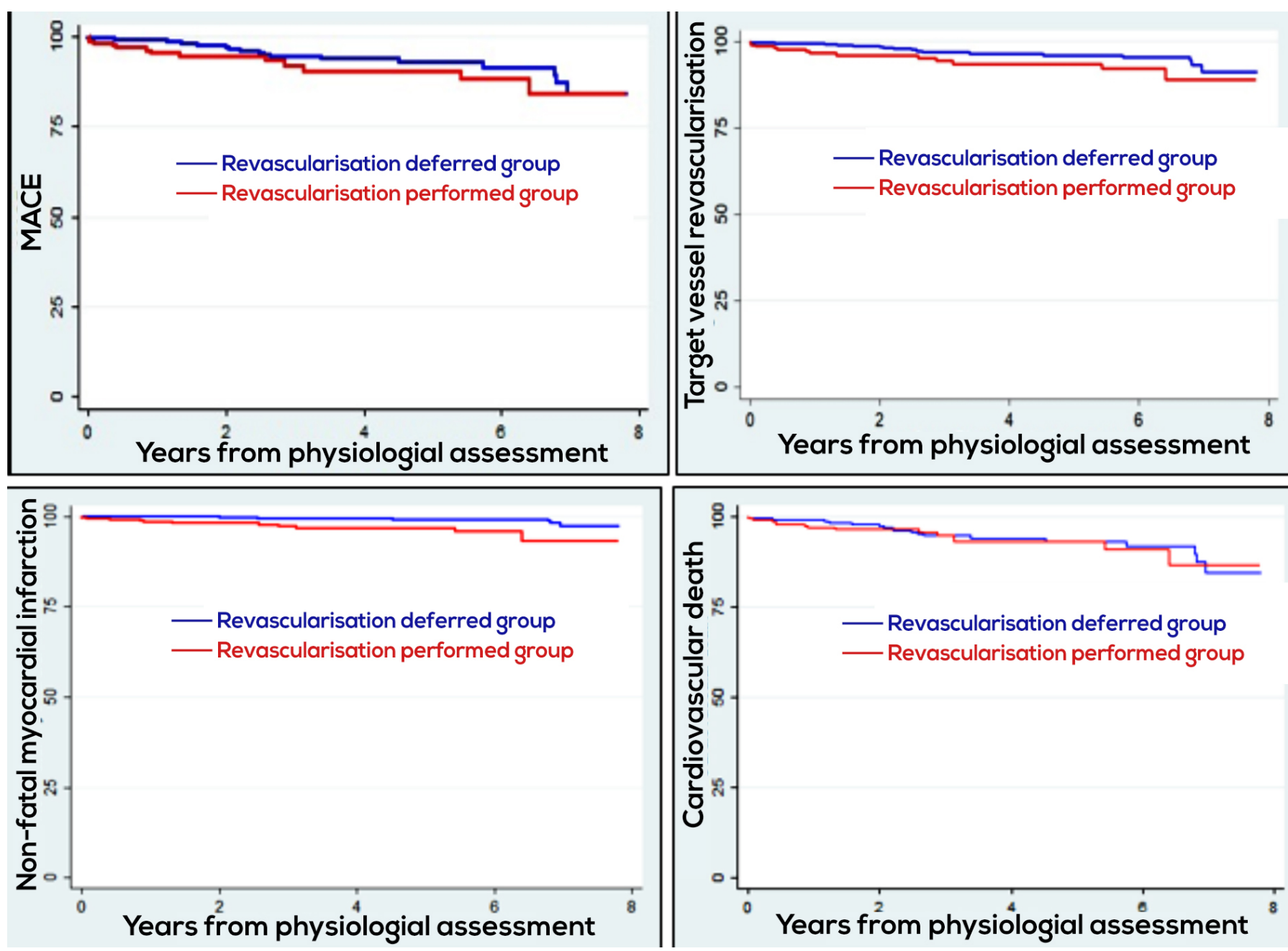

Figure 2: Kaplan meir curve showing MACE, target vessel revascularisation, non-fatal MI, and cardiovascular death.

To the best of authors' knowledge, this is the first and largest study on long-term outcomes of physiological assessment-based revascularisation from Pakistan. These results follow trends in outcomes similar to studies from other countries. To generate a more robust local research data, a prospective multicentre randomised study should be performed.

This study has several limitations. First, it is a single-centre retrospective observational study, and hence has limited generalisability. Second, a longer follow-up is needed to validate the present results. Although the follow-up period was indeed long, index case tracing and response from patients were difficult for cases enrolled in the earlier years of study induction.

\section{CONCLUSION}

Physiological assessment of coronary lesions led to a better selection of patients for revascularisation. It prevented mislabelling of intermediate coronary stenoses and averted unnecessary interventions, in turn leading to a decrease in complications of procedures, and use of dual antiplatelets.

\section{ETHICAL APPROVAL:}

Approval from Ethical Review Committee, The Aga Khan University Hospital Karachi, Pakistan taken before initiation of study (ERC No. 2020-5089-11578).

\section{PATIENTS' CONSENT:}

Informed consent not required as it is a retrospective study and patient identity was kept anonymous.

\section{CONFLICT OF INTEREST:}

The authors declared no conflict of interest.

\section{AUTHORS' CONTRIBUTION:}

NR, GA, JA: Designed the manuscript.

GA, JA: Collected the data.

AF, IU: Involved in analysis of the data. The initial manuscript was written by Dr. Ghufran.

$A F, J A, I U, M N R, G A$ : Contributed significantly in writing and critical revision of manuscript.

All authors have read and approved the manuscript.

\section{REFERENCES}

1. Turin TC, Shahana N, Wangchuk LZ, Specogna AV, AI Mamun M, Khan MA, et al. Burden of cardio-and cerebro-vas- 
cular diseases and the conventional risk factors in South Asian population. Glob Heart 2013; 8(2):121-30. doi: 10.1016/j.gheart.2012.01.001.

2. Yusuf S, Rangarajan S, Teo K, Islam S, Li W, Liu L, et al. Cardiovascular risk and events in 17 low, middle, and high-income countries. N Engl J Med 2014; 371(9):818-27. doi: 10.1056/NEJMoa1311890.

3. Zir LM, Miller SW, Dinsmore RE, Gilbert JP, Harthorne JW. Interobserver variability in coronary angiography. Circulation 1976; 53(4):627-32. doi: 10.1161/01.cir.53.4.627.

4. Baumann S, Chandra L, Skarga E, Renker M, Borggrefe M, Akin I, et al. Instantaneous wave-free ratio (IFR) to determine hemodynamically significant coronary stenosis: A comprehensive review. World J Cardiol 2018; 10(12): 267-77. doi: 10.4330/wjc.v10.i12.267.

5. Al-Obaidi FR, Fearon WF, Yong AS. Invasive physiological indices to determine the functional significance of coronary stenosis. Int J Cardiol Heart Vasc 2018; 18:39-45. doi: 10.1016/j.ijcha.2018.02.003.

6. Tonino PA, De Bruyne B, Pijls NH, Siebert U, Ikeno F. vant Veer $M$, et al. Fractional flow reserve versus angiography for guiding percutaneous coronary intervention. N Engl J Med 2009; 360(3):213-24. doi: 10.1056/NEJMoa0807611.

7. De Bruyne B, Pijls NH, Kalesan B. FAME 2 Trial Investigators. Fractional flow reserve-guided $\mathrm{PCl}$ versus medical therapy in stable coronary disease. N Engl J Med 2012; 367(11): 991-1001. doi: 10.1056/NEJMoa1205361.

8. Davies JE, Sen S, Dehbi HM, Al-Lamee R, Petraco R, Nijjer $\mathrm{SS}$, et al. Use of the instantaneous wave-free ratio or fractional flow reserve in $\mathrm{PCl}$. N Engl J Med 2017; 376(19): 1824-34. doi: 10.1056/NEJMoa1700445.

9. Jayawardena R, Ranasinghe P, Byrne NM, Soares MJ, Katulanda P, Hills AP. Prevalence and trends of the diabetes epidemic in South Asia: A systematic review and meta-analysis. BMC Public Health 2012; 12(1):1-1. doi: 10.1186/ 1471-2458-12-380.

10. Volgman AS, Palaniappan LS, Aggarwal NT, Gupta M, Khandelwal A, Krishnan AV, et al. Atherosclerotic cardiovascular disease in South Asians in the United States: epidemiology, risk factors, and treatments: A scientific statement from the American Heart Association. Circulation 2018; 138(1): e1-34. doi: 10.1161/CIR.0000000000000580.

11. Warisawa T, Cook CM, Akashi YJ, Davies JE. Past, present and future of coronary physiology. Rev Esp Cardiol (Engl
Ed). 2018; 71(8):656-67. doi: 10.1016/j.rec.2018.02.003.

12. Curzen N, Rana O, Nicholas Z, Golledge P, Zaman A, Oldroyd $K$, et al. Does routine pressure wire assessment influence management strategy at coronary angiography for diagnosis of chest pain? The RIPCORD study. Circ Cardiovasc Interv 2014; 7(2):248-55. doi: 10.1161/CIRCINTERVENTIONS.113.000978.

13. Layland J, Oldroyd KG, Curzen N, Sood A, Balachandran K, Das $R$, et al. Fractional flow reserve vs. angiography in guiding management to optimize outcomes in non-ST-segment elevation myocardial infarction: The british heart foundation famous-nstemi randomized trial. Eur Heart J 2015; 36(2):100-11. doi: 10.1093/eurheartj/ehu338.

14. Härle T, Zeymer U, Hochadel M, Zahn R, Kerber S, Zrenner $B$, et al. Real-world use of fractional flow reserve in Germany: Results of the prospective ALKK coronary angiography and $\mathrm{PCl}$ registry. Clin Res Cardiol 2017; 106(2): 140-50. doi: 10.1007/s00392-016-1034-5.

15. Baptista SB, Raposo L, Santos L, Ramos R, Calé R, Jorge E, et al. Impact of routine fractional flow reserve evaluation during coronary angiography on management strategy and clinical outcome: One-year results of the post-it multicenter registry. Circ Cardiovasc Interv 2016; 9(7):e003288. doi: 10.1161/CIRCINTERVENTIONS.115.003288.

16. Fearon WF, Nishi T, De Bruyne B, Boothroyd DB, Barbato E, Tonino $P$, et al. Clinical outcomes and cost-effectiveness of fractional flow reserve-guided percutaneous coronary intervention in patients with stable coronary artery disease: Three-year follow-up of the fame 2 trial (fractional flow reserve versus angiography for multivessel evaluation). Circulation 2018; 137(5):480-7. doi: 10.1161/CIRCULATIONAHA.117.031907.

17. Prasad S, Harikrishnan S, Sanjay G, Abhilash SP, Bijulal S, Kumar MK, et al. Clinical outcomes of patients with coronary artery disease who underwent FFR evaluation of intermediate coronary lesions-COFFRS study. Indian Heart J 2017; 69(4):499-504. doi: 10.1016/j.ihj.2016.12.007.

18. Kennedy MW, Kaplan E, Hermanides RS, Fabris E, Hemradj V, Koopmans PC, et al. Clinical outcomes of deferred revascularisation using fractional flow reserve in patients with and without diabetes mellitus. Cardiovascular Diabetol 2016; 15(1):1-8. doi: 10.1186/s12933-016-0417-2.

19. Doh JH, Nam CW, Koo BK, Park SH, Lee JH, Han JK, et al. Long-term patient-related and lesion-related outcomes after real-world fractional flow reserve use. J Invasive Cardiol 2015; 27(410):5. 